\title{
The formation of dunes, antidunes, and rapidly damping waves in alluvial channels
}

\author{
L.-H. Huang*,† and Y.-L. Chiang \\ Department of Civil Engineering and Hydrotech Research Institute, National Taiwan University, Taipei, 10617, Taiwan, ROC
}

\begin{abstract}
SUMMARY
Under the effect of a constant current for a long time, a water channel of infinitely long and constant depth interacting with a uniform sandbed of infinite thickness is used to simulate the formation of dunes, antidunes and rapidly damping waves in alluvial channels. The theory of potential flow is applied to the channel flow, while Biot's theory of poroelasticity is adopted to deal with erodible bed material. The governing equations, together with free surface, bed surface, and far field boundary conditions, form a complete boundary-value problem without applying empirical sediment discharge formulas as in conventional researches. The comparison of the present result with Kennedy's (Journal of Fluid Mechanics, 1963; 16: 521-544) instability analysis not only indicates the appropriateness of the present work, but also reveals the advantage of the present study due to its ability to find all kinds of bed forms (including the rapidly damping waves that Kennedy could not find) and of solving for the unclear lagged distance $\delta$ introduced in Kennedy's work. Copyright (C) 2001 John Wiley \& Sons, Ltd.
\end{abstract}

KEY WORDS: alluvial channel; poroelastic bed; bed-form formation

\section{INTRODUCTION}

Bed-form formation in alluvial channels is one of the most important problems in hydraulic engineering. Water flow of the channel and bed-form formation are interrelated. During the interrelated deforming process, both water-surface oscillation and bed erosion, or deposition, are found. To predict the final shapes of water surface, bed form and the sediment discharge are important subjects to most hydraulic engineers and researchers.

In the early days, Darwin [1] conducted experiments on sand-ripple formation due to oscillatory motion. Sleath [2] then derived the analytical solution for the wavelength of a 'rollingripple' due to oscillatory flow over a wavy rigid bed. More recently, Blondeaux [3], Vittori and

\footnotetext{
* Correspondence to: L.-H. Huang, Department of Civil Engineering and Hydrotech Research Institute, National Taiwan University, Taipei, 10617, Taiwan, Republic of China.

${ }^{\dagger}$ E-mail: lhhwang@ce.ntu.edu.tw

Contract/grant sponsor: National Science Council of the Republic of China; Contract/grant No: NSC84-2211-E002-043

Copyright (C) 2001 John Wiley \& Sons, Ltd.

Received 10 April 2000 Revised 15 September 2000
} 
Blondeaux [4], and Vittori and Blondeaux [5] undertook a series of studies on sand ripples due to sea waves. On the other hand, Exner [6] established a differential erosion equation for two-dimensional flow. This equation indicates that the change in bed elevation is due to longitudinal variation of bottom velocity. Liu [7] thus claimed that the sandbed behaves like viscous fluid, and obtained ripple formation based on Exner's [6] differential equation.

However, the mechanism of the formation of dune and antidune is somehow different from that of a ripple. As stated by Graf [8], the alluvial bed form for 'low water' is mainly caused by skin drag; thus the viscous effect is dominant. However the bed form for 'high water' is mainly due to form drag; hence pressure gradient is important. Indeed, Kennedy [9] did treat the bed as a continuum and applied the instability analysis of a potential channel flow combined with an empirical bed load sediment discharge formula to obtain his famous results of dune and antidune formations in alluvial channels. Unfortunately, due to the constraint of instability analysis, Kennedy [9] could only find the dominant wave number of stable bed forms instead of all bed forms. (Note that sand wave amplitude grows to infinity as time goes to infinity except in the cases of $\operatorname{Re}\left(k_{0} \delta\right)$ where it equals 0 or $\pi$ in Kennedy's work.) On the other hand, because of the introduction of an empirical sediment discharge formula, an unclear lagged distance $\delta$ of sediment discharge from flow velocity existed in Kennedy's work.

Recently, Huang and Song [10] studied the interaction between water wave and sandbed by applying potential theory to deal with water waves in the channel, and using three decoupled Helmholtz equations derived in Huang and Chwang [11] to handle the poroelastic sandbed material. As a result, Huang and Song [10] provided a useful tool to solve problems of channel-flow/sandbed interaction as long as pressure gradient is dominant.

Under the effect of a constant current for a long time, a water channel of infinite length and constant depth interacting with a uniform sandbed of infinite thickness is taken to simulate the formation of dunes, antidunes and rapidly damping waves in alluvial channels in the present work. By using an approach similar to that in Huang and Song [10], we solved the present problem. The present work deals with a complete boundary-value problem instead of performing instability analysis with empirical sediment discharge formula like Kennedy's [9]. Still, we find that the present result not only confirms the experimental data of Kennedy [9], but is also capable of finding all kinds of bed forms (including rapidly damping wave that Kennedy [9] could not find) and solving the unclear lagged distance $\delta$ that has bothered researchers in river mechanics for many years.

\section{THEORY}

On observing channel-water/sandbed interaction in a short period of time, we find that water surface undulates rapidly and the sandbed does not act like a continuum (see Figure 1). However, beside Kennedy's [9] results, in the observation of channel-water/sandbed interaction over a long period of time, it is found that water surface oscillates with low frequency and the sandbed acts like a continuum (see Figure 2).

Based upon the above discussion, we are allowed to treat the problem of long-time-period dune, antidune, and rapidly damping-wave formations in alluvial channels (indicated schematically as in Figure 3) by applying conventional potential theory to channel flow and adopting poroelastic theory (see Biot [12]) to sandbed material. In Figure 3, potential-channel flow is denoted by Region I, while the poroelastic sandbed is denoted by Region II. Constant channel 


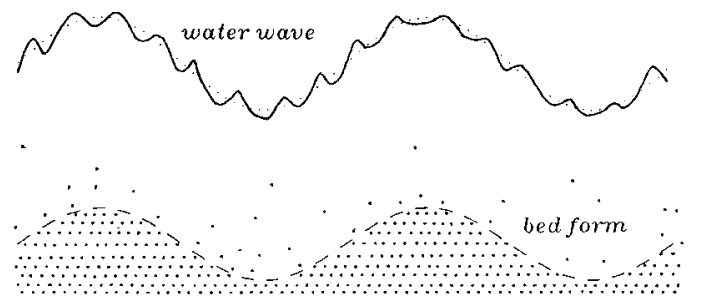

Figure 1. Short-time period observation of water wave and bed form in alluvial channel.
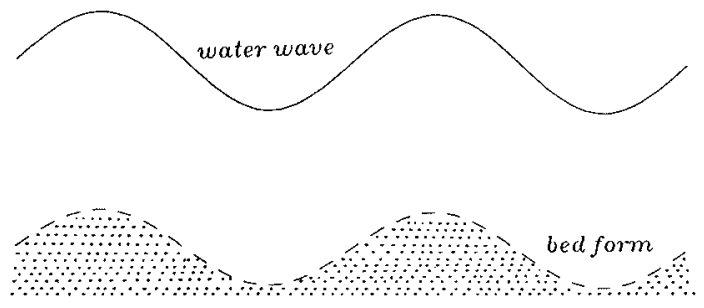

Figure 2. Long-time period observation of water wave and bed form in alluvial channel.

current $U$ and a stable low frequency water wave with displacement $\xi^{*}$ cause a low frequency sand wave with displacement $\eta^{*}$ in the channel of mean depth $h . A_{\mathrm{w}}$ and $A_{\mathrm{b}}$ are water wave and sand wave amplitudes respectively; $k_{0}$ is the complex wave number in the $x$-direction (the real part of $k_{0}$ equals $2 \pi / L$, where $L$ is the wavelength, and it is equivalent to the dominant wave number discussed in Kennedy [9] when the bed form is stable); $\omega$ is the angular frequency of the water wave ( $\omega=2 \pi / T$, where $T$ is wave period); $\theta$ is the lagged distance of the sand wave from the water wave. The coordinates are arranged so that $-\infty<x<\infty,-h \leqslant y \leqslant 0$ for Region I, while $-\infty<x<\infty,-\infty<y \leqslant-h$ for Region II.

\subsection{Formulation}

For a linear problem, stable water waves and sand waves may have a time factor $\mathrm{e}^{-\mathrm{i} \omega t}$, hence it is convenient to denote the time-dependent variables as

$$
[]^{*}=[] \mathrm{e}^{-\mathrm{i} \omega t}
$$

beforehand.

In Region I ( $-\infty<x<\infty,-h \leqslant y \leqslant 0)$, the channel flow, given a water wave

$$
\xi^{*}=A_{\mathrm{w}} \mathrm{e}^{\mathrm{i}\left(k_{0} x-\omega t\right)}
$$

the flow velocity $\mathbf{V}^{*}$ and its velocity potential $\Phi^{*(1)}$ have a relation

$$
\mathbf{V}^{*}=\nabla \Phi^{*(1)}
$$

because flow is irrotational. Since the flow velocity may be written as a given constant current $U$ in $x$-direction plus a perturbed velocity $\mathbf{u}^{*}$,

$$
\mathbf{V}^{*}=U \mathbf{e}_{x}+\mathbf{u}^{*}
$$




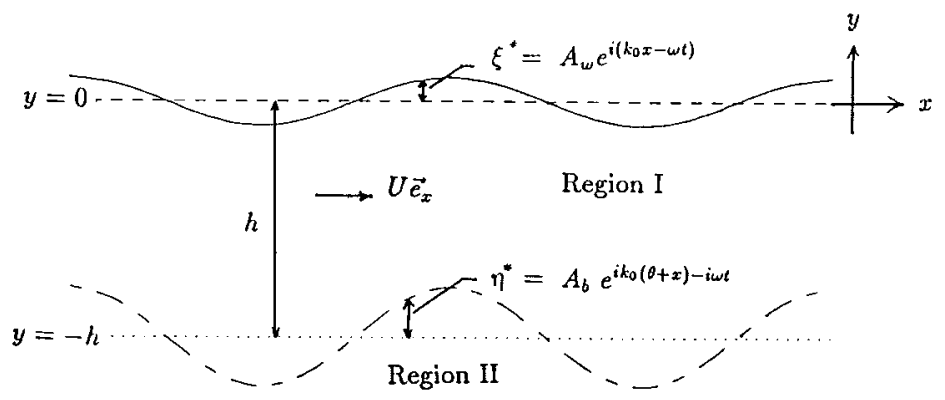

Figure 3. Schematic diagram of problem.

By letting

$$
\Phi^{*(1)}=U x+\phi^{*(1)}
$$

we then have

$$
\mathbf{u}=\nabla \phi^{(1)}
$$

with

$$
\nabla^{2} \phi^{(1)}=0
$$

as the continuity equation of the perturbed flow velocity $\mathbf{u}$.

On the other hand, it can be seen easily that the conventional linear momentum equation of the channel flow is

$$
P^{*(1)}=\rho_{\mathrm{f}}\left\{-g \xi^{*}+\mathrm{i} \omega \phi^{*(1)}-U \phi_{, x}^{*(1)}\right\}
$$

where $P^{*(1)}$ is the perturbed pressure in Region I due to water wave and flow, $\rho_{\mathrm{f}}$ is water density, and $g$ is gravitational acceleration.

In Region II $(-\infty<x<\infty,-\infty<y \leqslant-h)$, the poroelastic sandbed, referring to Huang and Chwang [11], the linear momentum equations of solid skeleton and fluid inside the porous bed, based on the theory of poroelasticity, can be written as

$$
\begin{aligned}
& \nabla \cdot \boldsymbol{\sigma}^{*}=\rho_{11} \frac{\partial^{2} \mathbf{d}^{*}}{\partial t^{2}}+\rho_{12} \frac{\partial^{2} \mathbf{D}^{*}}{\partial t^{2}}+b\left(\frac{\partial \mathbf{d}^{*}}{\partial t}-\frac{\partial \mathbf{D}^{*}}{\partial t}\right) \\
& \nabla \cdot \mathbf{S}^{*}=\rho_{12} \frac{\partial^{2} \mathbf{d}^{*}}{\partial t^{2}}+\rho_{22} \frac{\partial^{2} \mathbf{D}^{*}}{\partial t^{2}}-b\left(\frac{\partial \mathbf{d}^{*}}{\partial t}-\frac{\partial \mathbf{D}^{*}}{\partial t}\right)
\end{aligned}
$$

with

$$
\begin{aligned}
\boldsymbol{\sigma}^{*} & =\tau^{*}-\left(1-n_{0}\right) P^{*(2)} \mathbf{I} \\
\tau^{*} & =2 G \mathbf{e}^{*}+\lambda\left(\nabla \cdot \mathbf{d}^{*}\right) \mathbf{I} \\
e_{i j}^{*} & =\left(d_{i, j}^{*}+d_{j, i}^{*}\right) / 2 \\
\mathbf{S}^{*} & =-n_{\mathrm{o}} P^{*(2)} \mathbf{I}
\end{aligned}
$$




$$
\begin{aligned}
\rho_{11} & =\left(1-n_{\mathrm{o}}\right) \rho_{\mathrm{s}}+\rho_{\mathrm{a}} \\
\rho_{12} & =-\rho_{\mathrm{a}} \\
\rho_{22} & =n_{\mathrm{o}} \rho_{\mathrm{f}}+\rho_{\mathrm{a}} \\
b & =\mu n_{\mathrm{o}}^{2} / k_{\mathrm{p}}
\end{aligned}
$$

where $\sigma^{*}$ is the solid stress tensor, $\tau^{*}$ is the effective stress tensor of the solid skeleton, $\mathbf{S}^{*}$ is the normal stress tensor of the fluid, $\mathbf{d}^{*}$ and $\mathbf{D}^{*}$ are solid and fluid displacement vectors, respectively. $P^{*(2)}$ is perturbed pressure of fluid inside the porous medium, $\rho_{\mathrm{s}}$ is solid density, $\rho_{\mathrm{a}}$ is the mass coupling effect (which is neglected in the present study), $n_{\mathrm{o}}$ is porosity, $\mu$ is the dynamic viscosity of fluid, $k_{\mathrm{p}}$ is specific permeability, $G$ and $\lambda$ are Lame constants of elasticity, and $\mathbf{I}$ is the identity matrix. We also find the storage equation as

$$
\frac{\partial P^{*(2)}}{\partial t}=-\frac{K}{n_{\mathrm{o}}}\left[\left(1-n_{\mathrm{o}}\right) \nabla \cdot\left(\frac{\partial \mathbf{d}^{*}}{\partial t}\right)+n_{\mathrm{o}} \nabla \cdot\left(\frac{\partial \mathbf{D}^{*}}{\partial t}\right)\right]
$$

for perturbed pressure due to deformation of the porous medium from conservation of mass. $K$ in the above equation is the bulk modulus of compressibility of fluid inside the porous medium.

Referring to Huang and Chwang [11] for the decoupling processes of Biot's [12] equations of poroelasticity, we may then introduce two scalar potentials $\phi_{1}^{(2)}, \phi_{2}^{(2)}$, and one vector potential $\mathbf{H}^{(2)}$ to represent two (in-phase and out-of-phase) longitudinal waves and one transverse wave, respectively as

$$
\begin{aligned}
\mathbf{d} & =\nabla \phi_{1}^{(2)}+\nabla \phi_{2}^{(2)}+\nabla \times \mathbf{H}^{(2)} \\
\mathbf{D} & =\alpha_{1} \nabla \phi_{1}^{(2)}+\alpha_{2} \nabla \phi_{2}^{(2)}+\alpha_{3} \nabla \times \mathbf{H}^{(2)}
\end{aligned}
$$

where $\mathbf{d}$ and $\mathbf{D}$ are displacement vectors of solid skeleton and fluid, respectively, after getting rid of time factor $\mathrm{e}^{-\mathrm{i} \omega t}$. Then, by applying (20) and (21) into (9) and (10), we may obtain three decoupled Helmholtz equations as

$$
\begin{gathered}
\nabla^{2} \phi_{j}^{(2)}+k_{j}^{2} \phi_{j}^{(2)}=0, \quad j=1,2 \\
\nabla^{2} \mathbf{H}^{(2)}+k_{3}^{2} \mathbf{H}^{(2)}=\mathbf{0}
\end{gathered}
$$

where $k_{1}, k_{2}, k_{3}$ are wave numbers defined by

$$
\begin{aligned}
k_{1}^{2}+k_{2}^{2} & =\frac{A_{1} R_{0}-2 A_{2} Q+(2 G+A) A_{3}}{(2 G+A) R_{0}-Q^{2}} \\
k_{1}^{2} k_{2}^{2} & =\frac{A_{1} A_{3}-A_{2}^{2}}{(2 G+A) R_{0}-Q^{2}} \\
k_{3}^{2} & =\frac{A_{1}-A_{2}^{2} / A_{3}}{G}
\end{aligned}
$$

with

$$
\begin{aligned}
& A=\lambda+Q q \\
& Q=K\left(1-n_{\mathrm{o}}\right)
\end{aligned}
$$




$$
\begin{aligned}
R_{0} & =K n_{\mathrm{o}} \\
q & =\left(1-n_{\mathrm{o}}\right) / n_{\mathrm{o}} \\
A_{1} & =\omega\left[\omega\left(\left(1-n_{\mathrm{o}}\right) \rho_{\mathrm{s}}+\rho_{\mathrm{a}}\right)+i b\right] \\
A_{2} & =-\omega\left(\omega \rho_{\mathrm{a}}+i b\right) \\
A_{3} & =\omega\left[\omega\left(n_{\mathrm{o}} \rho_{\mathrm{o}}+\rho_{\mathrm{a}}\right)+i b\right]
\end{aligned}
$$

And fluid/solid related parameters are

$$
\begin{aligned}
& \alpha_{j}=\frac{-k_{j}^{2}\left[Q^{2}-(2 G+A) R_{0}\right]+\left(A_{2} Q-A_{1} R_{0}\right)}{A_{2} R_{0}-A_{3} Q}, j=1,2 \\
& \alpha_{3}=\frac{-A_{2}}{A_{3}} .
\end{aligned}
$$

Note that in the problem of Figure 3, due to the orientation of $y$-axis, we will need

$$
\operatorname{Im}\left(k_{j}\right)>0, \quad j=1,2,3
$$

for the imaginary part of wave numbers in order to keep energy dissipation positive.

By referring to Morse and Fesbach [13], we may let

$$
\mathbf{H}=\phi_{3}^{(2)} \mathbf{e}_{z}
$$

where $\mathbf{e}_{z}$ is unit vector in $z$-direction. Thus, (23) becomes

$$
\nabla^{2} \phi_{3}^{(2)}+k_{3}^{2} \phi_{3}^{(2)}=0
$$

And applying (22), (23) to (19), the storage equation can be written as

$$
\begin{aligned}
P^{(2)} & =\frac{K}{n_{\mathrm{o}}} \sum_{j=1}^{2}\left[\begin{array}{lll}
q_{j} & k_{j}^{2} & \phi_{j}^{(2)}
\end{array}\right] \\
q_{j} & =1-n_{\mathrm{o}}\left(1-\alpha_{j}\right), \quad j=1,2
\end{aligned}
$$

after getting rid of time factor $\mathrm{e}^{-\mathrm{i} \omega t}$.

There are three boundaries which require linear boundary conditions in this study. They are (a) water surface $(y=0)$, (b) channel bed interface $(y=-h)$, and (c) deep field of the porous bed $(y \rightarrow-\infty)$.

For water surface, we have kinematic boundary condition as

$$
\phi_{, y}^{*(1)}=\xi_{, t}^{*}, \quad y=0
$$

i.e.

$$
\phi_{, y}^{(1)}=\mathrm{i} A_{\mathrm{w}} \quad k_{0} c_{0} \mathrm{e}^{\mathrm{i} k_{0} x}, \quad y=0
$$

with

$$
c_{0}=U-\frac{\omega}{k_{0}}
$$


by referring to (2). We may also have vanishing pressure as the linear dynamic boundary condition on the free surface, i.e.

$$
g A_{\mathrm{w}} \mathrm{e}^{\mathrm{i} k_{0} x}+U \phi_{, x}^{(1)}-\mathrm{i} \omega \phi^{(1)}=0, \quad y=0
$$

according to (2) and (8).

On the channel bed interface, the linear kinematic boundary condition is (referred to (48) of Chen et al., [14])

$$
\eta=\phi_{1, y}^{(2)}+\phi_{2, y}^{(2)}-\phi_{3, x}^{(2)}, \quad y=-h
$$

((45) will be used to find $\eta$ only.). Thus, mass flux conservation becomes (referred to (22) and (41) to Chen et al., [14])

$$
\phi_{, y}^{(1)}=-\mathrm{i} \omega\left(\sum_{j=1}^{2}\left[q_{j} \phi_{j, y}^{(2)}\right]-q_{3} \phi_{3, x}^{(2)}\right)+U\left(\phi_{1, x y}^{(2)}+\phi_{2, x y}^{(2)}-\phi_{3, x x}^{(2)}\right), \quad y=-h
$$

where

$$
q_{3}=1-n_{\mathrm{o}}\left(1-\alpha_{3}\right)
$$

As for the linear dynamic boundary condition of fluid, it is the continuity of perturbed pressure (referred to (42) of Chen et al., [14]),

$$
\mathrm{i} \omega \phi^{(1)}-U \phi_{, x}^{(1)}=\frac{K}{\rho_{\mathrm{f}} n_{\mathrm{o}}} \sum_{j=1}^{2}\left[q_{j} k_{j}^{2} \phi_{j}^{(2)}\right], \quad y=-h
$$

(Note that $-\rho_{\mathrm{f}} g \xi$ terms at both sides of (48) cancel each other.) And the continuity of effective stress of the solid skeleton gives (referred to (43), (44) of Chen et al., [14])

$$
\begin{gathered}
2 \phi_{1, x y}^{(2)}+2 \phi_{2, x y}^{(2)}+\phi_{3, y y}^{(2)}-\phi_{3, x x}^{(2)}=0, \quad y=-h \\
\phi_{1, y y}^{(2)}+\phi_{2, y y}^{(2)}-\phi_{3, x y}^{(2)}-\frac{\lambda}{2 G}\left(k_{1}^{2} \phi_{1}^{(2)}+k_{2}^{2} \phi_{2}^{(2)}\right)=0, \quad y=-h
\end{gathered}
$$

For the far field of porous bed, the boundary conditions are vanishing displacement vectors, i.e.

$$
\phi_{j}^{(2)}=0, \quad j=1,2,3, \quad y \rightarrow-\infty
$$

according to (20), (21) and (37).

Governing equations (7), (22), and (38), together with boundary conditions (42), (44), (46), and (48)-(51), form a complete boundary-value-problem to be solved.

\subsection{Solution}

Based on (7) and (42), we may propose

$$
\phi^{(1)}=\left(D \cosh \left(k_{0} y\right)+E \sinh \left(k_{0} y\right)\right) \mathrm{e}^{\mathrm{i} k_{0} x}, \quad \operatorname{Re}\left(k_{0}\right) \operatorname{Im}\left(k_{0}\right) \geqslant 0
$$

And then (42) and (44) give

$$
\begin{gathered}
E=\mathrm{i} c_{0} A_{\mathrm{w}} \\
D=\frac{\mathrm{i} g A_{\mathrm{w}}}{k_{0} c_{0}}
\end{gathered}
$$


In order to satisfy governing equations (22), (38), and boundary conditions at $y=-h$, we may have

$$
\phi_{j}^{(2)}=\frac{a_{j}}{k_{0}^{2}} \mathrm{e}^{K_{j}(y+h)} \mathrm{e}^{\mathrm{i} k_{0} x}, \quad j=1,2,3, \quad \operatorname{Re}\left(K_{j}\right)>0
$$

with

$$
K_{j}^{2}=k_{0}^{2}-k_{j}^{2}, \quad j=1,2,3
$$

by referring to (51). Then, (49) and (50) give

$$
\begin{gathered}
L_{1} a_{1}+L_{2} a_{2}+a_{3}=0 \\
H_{1} a_{1}+H_{2} a_{2}=0
\end{gathered}
$$

with

$$
\begin{aligned}
L_{j} & =\frac{2 \mathrm{i} K_{j} / k_{0}}{1+K_{3}^{2} / k_{0}^{2}}, \quad j=1,2 \\
H_{j} & =\frac{K_{j}^{2}}{k_{0}^{2}}-\frac{\lambda}{2 G} \frac{k_{j}^{2}}{k_{0}^{2}}+\mathrm{i} \frac{K_{3}}{k_{0}} L_{j}, \quad j=1,2
\end{aligned}
$$

Further, applying (55) into (46), together with (57) and (58), we have

$$
a_{1}=\frac{H_{2} A_{\mathrm{w}}}{c_{0}^{2} T_{1}}\left[-g \sinh \left(k_{0} h\right)+k_{0} c_{0}^{2} \cosh \left(k_{0} h\right)\right]
$$

where

$$
\begin{aligned}
T_{1} & =\frac{c_{1} K_{1}}{c_{0} k_{0}} H_{2}-\frac{c_{2} K_{2}}{c_{0} k_{0}} H_{1}+\mathrm{i} \frac{c_{3}}{c_{0}}\left(L_{1} H_{2}-L_{2} H_{1}\right) \\
c_{j} & =U-\frac{\omega}{k_{0}} q_{j}, \quad j=1,2,3
\end{aligned}
$$

And, of course, we may then get

$$
\begin{gathered}
a_{2}=-\frac{H_{1}}{H_{2}} a_{1} \\
a_{3}=-L_{1} a_{1}-L_{2} a_{2}
\end{gathered}
$$

according to (57) and (58).

Finally, by substituting the solutions of (52) and (55) into (48), the last boundary condition, the dispersion relation is obtained as

$$
\left(1-\frac{k_{0} c_{0}^{2}}{g} T_{3}\right) \sinh \left(k_{0} h\right)=\left(\frac{k_{0} c_{0}^{2}}{g}-T_{3}\right) \cosh \left(k_{0} h\right)
$$

where

$$
T_{3}=\frac{n_{\mathrm{o}} \rho_{\mathrm{f}} c_{0}^{2}}{K} \frac{T_{1}}{T_{2}}
$$


with $T_{1}$ given by (62) and

$$
T_{2}=q_{1} H_{2} \frac{k_{1}^{2}}{k_{0}^{2}}-q_{2} H_{1} \frac{k_{2}^{2}}{k_{0}^{2}}
$$

(66) is going to be used to determine $k_{0}$. Note that $k_{0}$ is now a complex number (i.e. including both propagating and damping parts) instead of a real number (i.e. only propagating part) as in Kennedy [9]. We will find that the real part of $k_{0}$ is equivalent to the dominant wave number in Kennedy [9] when the bed form is stable.

After potential functions $\phi^{(1)}, \phi_{1}^{(2)}, \phi_{2}^{(2)}, \phi_{3}^{(2)}$, and wave number $k_{0}$ are found, we find perturbed velocity components and perturbed pressure of flow in Region I, perturbed pressure (due to deformation of porous medium only) in Region II, and sand wave displacement analytically as

$$
\begin{aligned}
u_{x} & =-A_{\mathrm{w}}\left[\frac{g}{c_{0}} \cosh \left(k_{0} y\right)+k_{0} c_{0} \sinh \left(k_{0} y\right)\right] \mathrm{e}^{\mathrm{i} k_{0} x} \\
& =v(y) \mathrm{e}^{\mathrm{i} k_{0}\left(x+\theta^{\prime \prime}\right)} \\
u_{y} & =\mathrm{i} A_{\mathrm{w}}\left[\frac{g}{c_{0}} \sinh \left(k_{0} y\right)+c_{0} k_{0} \cosh \left(k_{0} y\right)\right] \mathrm{e}^{\mathrm{i} k_{0} x} \\
P^{(1)} & =\rho_{\mathrm{f}}\left\{-g \xi-\mathrm{i} A_{\mathrm{w}}\left[g \cosh \left(k_{0} y\right)+k_{0} c_{0}^{2} \sinh \left(k_{0} y\right)\right] \mathrm{e}^{\mathrm{i} k_{0} x}\right\} \\
P^{(2)} & =\frac{K}{n_{\mathrm{o}}} \sum_{j=1}^{2} q_{j} a_{j} \frac{k_{j}^{2}}{k_{0}^{2}} \mathrm{e}^{K_{j}(y+h)+\mathrm{i} k_{0} x} \\
\eta & =\left(\frac{K_{1} a_{1}}{k_{0}^{2}}+\frac{K_{2} a_{2}}{k_{0}^{2}}-\mathrm{i} \frac{a_{3}}{k_{0}}\right) \mathrm{e}^{\mathrm{i} k_{0} x} \\
& =A_{\mathrm{b}} \mathrm{e}^{\mathrm{i} k_{0}(x+\theta)}
\end{aligned}
$$

according to (6), (8), (19), and (45). In (69), the lagged distance of flow velocity from water wave $\theta^{\prime \prime}$ will be used later to find $\delta$. In (73), $A_{\mathrm{b}}$ denotes the amplitude of sand wave, while $\theta$ is the lagged distance of the sand wave from the water wave.

\section{DISCUSSIONS}

Given solid density $\rho_{\mathrm{s}}$, Lame constants $G$, $\lambda$, and fluid density $\rho_{\mathrm{f}}$, bulk modulus of compressibility $K$, viscosity $\mu$, porosity $n_{\mathrm{o}}$, and specific permeability $k_{\mathrm{p}}$, we may obtain wave numbers $k_{1}, k_{2}, k_{3}$, and fluid/solid related parameters $\alpha_{1}, \alpha_{2}$, and $\alpha_{3}$ by applying (24)-(26) and (34)-(35) provided that wave period $T(T=2 \pi / \omega)$ is given. And we may calculate wave number $k_{0}$ by applying dispersion relation (66) if current speed $U$ and mean water depth $h$ are further given. ((66) does not have a unique root). One should notice from (61), (64)-(65), and (69)-(73) that water wave amplitude $A_{\mathrm{w}}$ only affects the magnitude and lagged distance of our physical variables, not the wave number $k_{0}$.

Referring to (73) and defining dissipation modulus as $\log \left[\operatorname{Im}\left(k_{0}\right) / \operatorname{Re}\left(k_{0}\right)\right]$, we may then divide the shapes of bed forms in the present study into three categories: (a) dune, (b) antidune, and (c) rapidly damping wave. When $\operatorname{Re}\left(k_{0} \theta\right) \simeq \pi$ (i.e. $\theta / L \simeq 0.5$ ), we have dunes; when $\operatorname{Re}\left(k_{0} \theta\right) \simeq 0$ (i.e. $\theta \simeq 0$ ), we have antidunes; when $\log \left[\operatorname{Im}\left(k_{0}\right) / \operatorname{Re}\left(k_{0}\right)\right]>0$, there is a rapidly damping wave. As for 
its direction of movement, the sand wave propagates downstream when $\operatorname{Re}\left(k_{0}\right)>0$, and upstream when $\operatorname{Re}\left(k_{0}\right)<0$.

We will use two characters and one number to denote the types of sand waves. The first character ( $\mathrm{d}$ or a or $\mathrm{f}$ ) represents dune, antidune, or flat bed. The second character $(\mathrm{u}$ or $\mathrm{d}$ ) represents moving upstream or downstream movement. And the number represents the group index. For example, ' $d d 1$ ' means the first group of downstream going dune, etc.

Defining Froude number as

$$
F=\frac{U}{\sqrt{g h}}
$$

and taking the solid line of Figure 9 in Kennedy [9] as the envelope curve, Figure 4 gives envelope curves of $F$ versus $\operatorname{Re}\left(k_{0} h\right)$ for very soft soil (see solid and fluid material properties given in Table 1) when $T=60 \mathrm{~s}$ and mean water depths $h$ equal $2,3 \mathrm{~m}$ respectively. (Note that $A_{\mathrm{w}}$ has nothing to do with this curve). From Figure 4 we realize that $h$ does not alter this curve. Figure 5 denotes the same envelope curve for materials in Tables 1 and 2, respectively, when $T=2 \mathrm{~s}$. Again, material properties are not effective factors to envelope curve of $F$ versus $\operatorname{Re}\left(k_{0} h\right)$. Figure 6 shows $F$ versus $\operatorname{Re}\left(k_{0} h\right)$ curves of very soft soil of Table 1 when $T$ are 2,10 , and $60 \mathrm{~s}$, respectively. It is found that, indeed, wave period does not have a severe effect on the $F$ versus $\operatorname{Re}\left(k_{0} h\right)$ curve. And Figure 6 indicates that as $T$ increases, the envelope curves become closer. From Figures 4 to 6 we find that the envelope curves of $F$ versus $\operatorname{Re}\left(k_{0} h\right)$ are mainly affected by wave period.

If we draw all the possible bed forms (i.e., not only the points on the envelope curve) of very soft soil of Table 1 with $A_{\mathrm{w}}=0.2 \mathrm{~m}, h=3 \mathrm{~m}, T=60 \mathrm{~s}$, we get $F$ versus $\operatorname{Re}\left(k_{0} h\right)$ as shown in Figure 7 . In Figure 7, eight possible kinds of bed forms such as dd1, dd2, du1, du2, ad1, ad2, fu, and fd are found. (Due to dissipation, we will find in the later discussion of Figure 10 that bed forms with $\mathrm{ad} 2, \mathrm{fu}$, and fd are difficult to observe experimentally.) Comparing Figure 7 to Figure 9 of Kennedy [9], we find that our result agrees with the experimental data as good as Kennedy's.

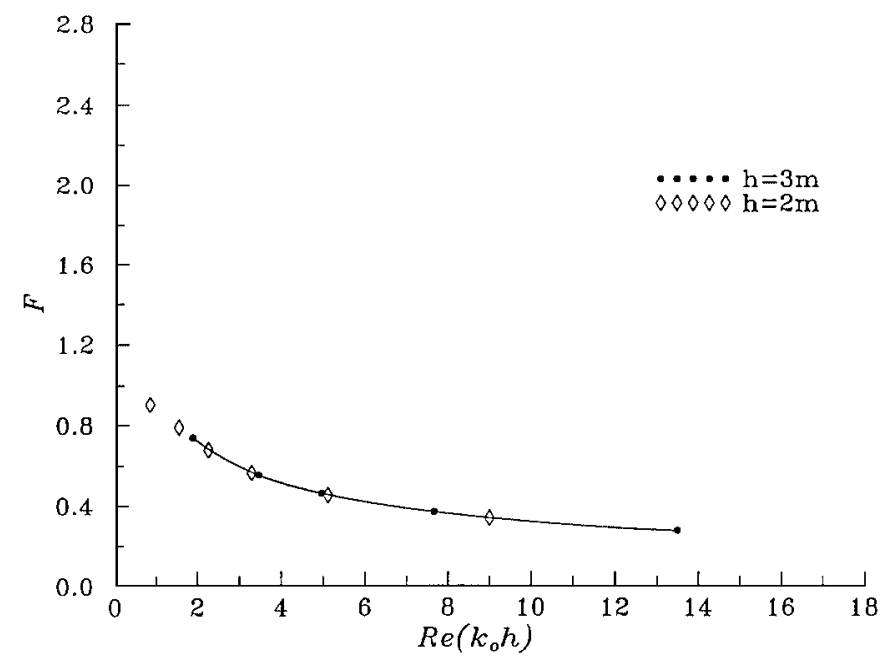

Figure 4. Envelope curve of $F$ versus $\operatorname{Re}\left(k_{0} h\right)$ for very soft soil when $T=60 \mathrm{~s}$ and $h=2,3 \mathrm{~m}$, respectively. 


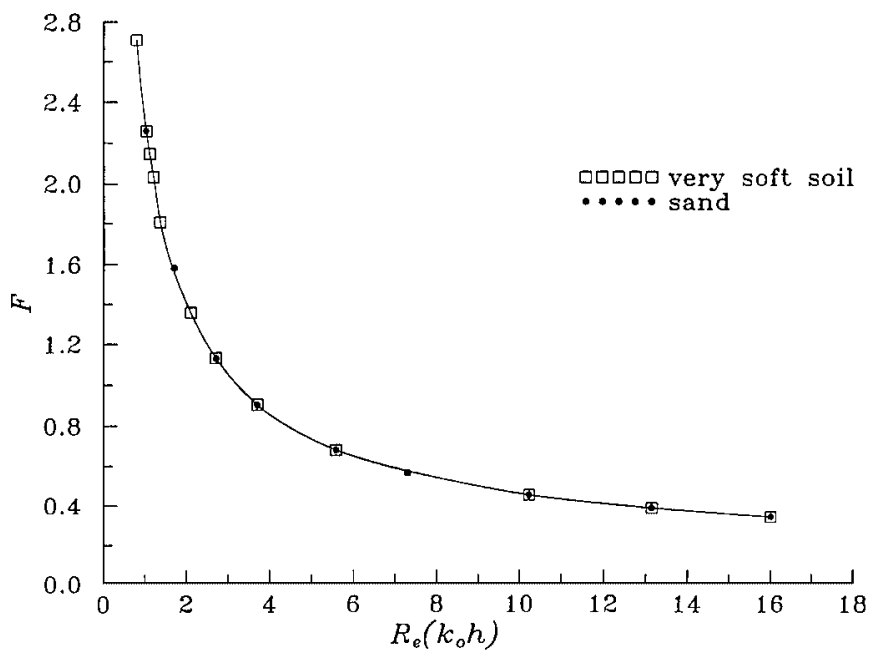

Figure 5. Envelope curve of $F$ versus $\operatorname{Re}\left(k_{0} h\right)$ for very soft soil and sand when $T=2 \mathrm{~s}$.

Table I. Material properties of very soft soil.

\begin{tabular}{|c|c|c|c|}
\hline $\begin{array}{l}\text { Items } \\
\text { (1) }\end{array}$ & $\begin{array}{c}\text { Symbols } \\
\text { (2) }\end{array}$ & $\begin{array}{l}\text { Values } \\
\text { (3) }\end{array}$ & $\begin{array}{l}\text { Notations } \\
\text { (4) }\end{array}$ \\
\hline \multicolumn{4}{|l|}{ (a) Water } \\
\hline Density & $\rho_{\mathrm{f}}$ & 1000 & $\mathrm{~kg} / \mathrm{m}^{3}$ \\
\hline Effective bulk modulus & $K$ & $2.3 \times 10^{9}$ & $\mathrm{Nt} / \mathrm{m}^{2}$ \\
\hline Dynamic viscosity & $\mu$ & 0.001 & $\mathrm{Nt} \mathrm{s} / \mathrm{m}^{2}$ \\
\hline \multicolumn{4}{|l|}{ (b) Skeleton } \\
\hline Density & $\rho_{\mathrm{s}}$ & 2650 & $\mathrm{~kg} / \mathrm{m}^{3}$ \\
\hline Lame's constant & $G$ & $5.0 \times 10^{4}$ & $\mathrm{Nt} / \mathrm{m}^{2}$ \\
\hline Lame's constant & $\lambda$ & $1.0 \times 10^{5}$ & $\mathrm{Nt} / \mathrm{m}^{2}$ \\
\hline Specific permeability & $k_{\mathrm{p}}$ & $1.0 \times 10^{-15}$ & $\mathrm{~m}^{2}$ \\
\hline Porosity & $n_{0}$ & 0.4 & - \\
\hline
\end{tabular}

And further, it not only gives better information about the type, the direction of movement, and the group of the bed forms than that of Kennedy [9], but also finds rapidly damping waves such as upstreaming going flat bed, downstream going flat bed, etc., which Kennedy [9] could not obtain. Because the formation of bed form ought to be the result of long-time-period wave (see the statement of the first paragraph of Section 2), the long-period-wave case $(T=60 \mathrm{~s})$ in Figure 7 therefore converages to Kennedy's [9] single-envelope curve Figure 9 nicely. From Figure 7 we find that the real part of $k_{0}$ in the present study is equivalent to the dominant wave number in Kennedy [9] when the bed form is stable.

For the purpose of comparing the present study with that of Kennedy [9], we follow Kennedy's way and represent our result in terms of $F$ versus $\operatorname{Re}\left(k_{0} h\right)$. In fact, the $F-\operatorname{Re}\left(k_{0} h\right)$ relation forces some upstream-going and downstream-going sand waves to fold together and this blurs the 
Table II. Material properties of sand.

\begin{tabular}{lccc}
\hline $\begin{array}{l}\text { Items } \\
\text { (1) }\end{array}$ & $\begin{array}{c}\text { Symbols } \\
(2)\end{array}$ & $\begin{array}{c}\text { Values } \\
(3)\end{array}$ & $\begin{array}{c}\text { Notations } \\
(4)\end{array}$ \\
\hline $\begin{array}{lcc}\text { (a) Water } \\
\text { Density }\end{array}$ & $\rho_{\mathrm{f}}$ & 1000 & $\mathrm{~kg} / \mathrm{m}^{3}$ \\
Effective bulk modulus & $K$ & $2.3 \times 10^{9}$ & $\mathrm{Nt} / \mathrm{m}^{2}$ \\
Dynamic viscosity & $\mu$ & 0.001 & $\mathrm{Nt} \mathrm{s} / \mathrm{m}^{2}$ \\
(b) Skeleton & & & \\
Density & $\rho_{\mathrm{s}}$ & 2650 & $\mathrm{~kg} / \mathrm{m}^{3}$ \\
Lame's constant & $G$ & $5.0 \times 10^{8}$ & $\mathrm{Nt} / \mathrm{m}^{2}$ \\
Lame's constant & $\lambda$ & $1.0 \times 10^{9}$ & $\mathrm{Nt} / \mathrm{m}^{2}$ \\
Specific permeability & $k_{\mathrm{p}}$ & $1.0 \times 10^{-12}$ & $\mathrm{~m}$ \\
Porosity & $n_{0}$ & 0.4 & - \\
\hline
\end{tabular}

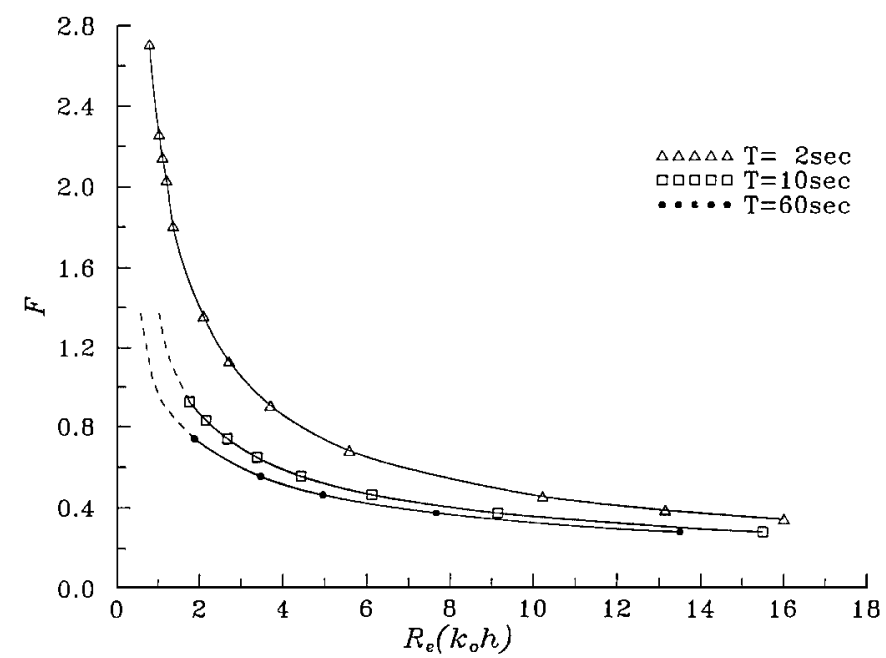

Figure 6. Envelope curve of $F$ versus $\operatorname{Re}\left(k_{0} h\right)$ for very soft soil when $T=2,10$ and 60 s, respectively.

physical identity of each sand wave (see dd2, du2 and fu, fd in Figure 7). With negative $L / h$ representing upstream going sand waves, Figure 8 reveals the result of Figure 7 by $F$ versus $L / h$. We can see from Figure 8 that the distribution of each kind of sand wave is now spreading out, and the transition of different types of sand waves becomes clearer compared to Figure 7.

The sediment continuity equation is

$$
\frac{\partial V^{*}}{\partial x}+\frac{\partial \eta^{*}}{\partial t}=0
$$

where $V^{*}$ is sediment transport volume per unit time, unit channel width. Applying (73), and taking $V^{*}$ at the valley of the sand wave as zero, we then may integrate (75) with respect to 


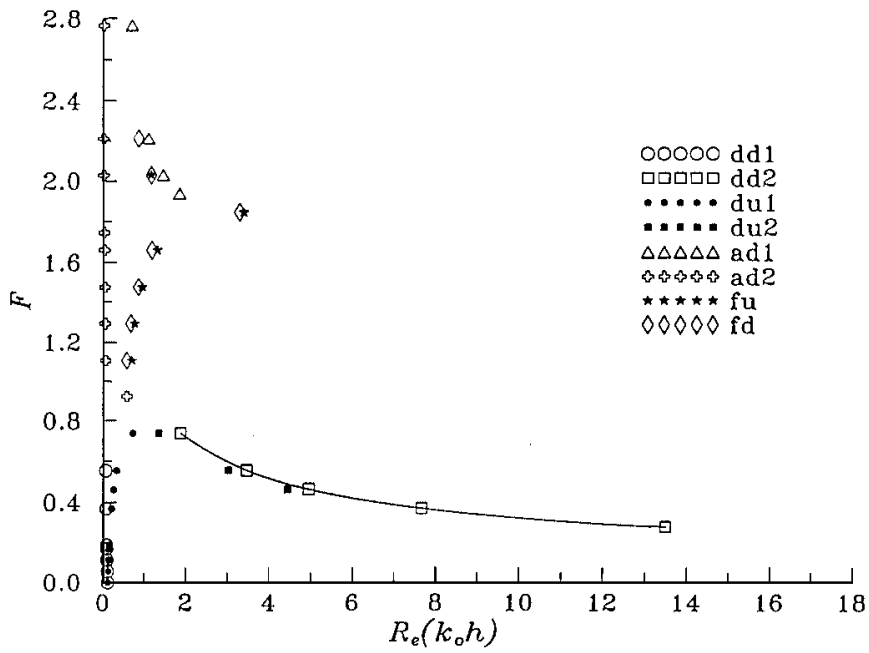

Figure 7. All possible $F$ versus $\operatorname{Re}\left(k_{0} h\right)$ relations of bed forms for very soft soil when $T=60 \mathrm{~s}$ and $h=3 \mathrm{~m}$.

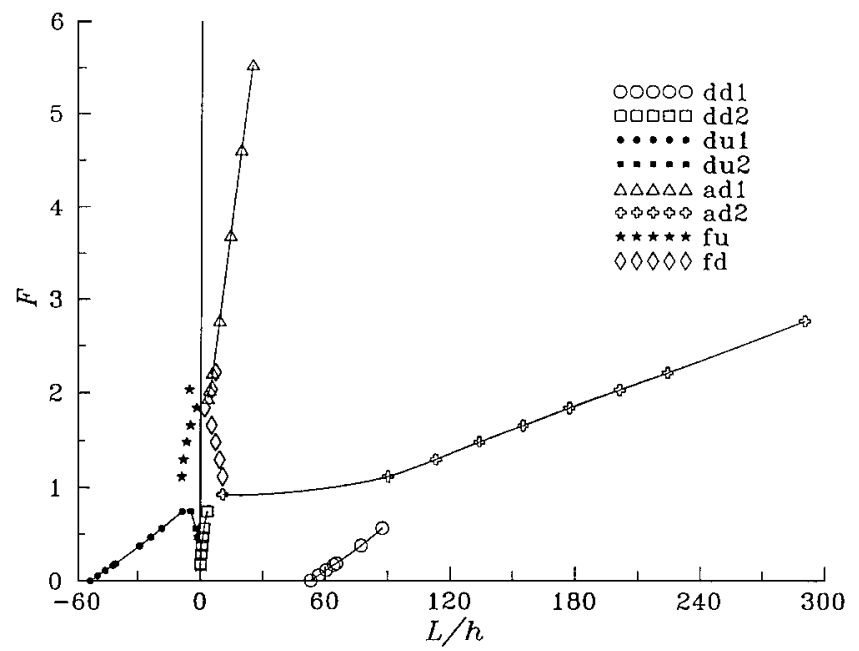

Figure 8. All possible $F$ versus $L / h$ relations of bed forms for very soft soil when $T=60 \mathrm{~s}$ and $h=3 \mathrm{~m}$.

$x$ and get

$$
\begin{aligned}
V^{*} & =\frac{\omega}{k_{0}} A_{\mathrm{b}} \mathrm{e}^{\mathrm{i} k_{0}(x+\theta)-\mathrm{i} \omega t}+\left|\frac{\omega}{k_{0}}\right| A_{\mathrm{b}} \\
& =\left|\frac{\omega}{k_{0}}\right| A_{\mathrm{b}}\left[1+\mathrm{e}^{\mathrm{i} k_{0}\left(\theta^{\prime}+x\right)-\mathrm{i} \omega t}\right]
\end{aligned}
$$

Further, integrating $V^{*}$ with respect to $x$ and $t$ for a wavelength $L$ and a wave period $T$, we have averaged sediment transport volume per unit channel width for a wavelength and a wave 
period as

$$
\bar{V}=\frac{1}{T L} \int_{0}^{T} \int_{0}^{L} V^{*} \mathrm{~d} x \mathrm{~d} t=\left|\frac{\omega}{k_{0}}\right| A_{\mathrm{b}}
$$

Figure 9 demonstrates $A_{\mathrm{b}} / A_{\mathrm{w}}, \bar{V} / A_{\mathrm{w}} \sqrt{g h}$ versus $F$ curves of the case in Figures 7 and 8 . (Note that $A_{\mathrm{w}}$ is $0.2 \mathrm{~m}$.) Figures 9(a) and 9(b) indicate that both $A_{\mathrm{b}} / A_{\mathrm{w}}$ and $\bar{V} / A_{\mathrm{w}} \sqrt{g h}$ increase as $F$ increases for a downstream-going dune, while it is the opposite for upstream-going dune. This means that when sand wave and current are in the same direction, current pushes and piles up the dune; on the other hand, when they are in opposite directions, current restricts the growth of dune. (Although the values of dd 2 in Figure 9(a) and du2 in Figure 9(b) are very small and almost unidentifiable, we will show in Figure 10 that they are still stable bed forms). Figure 9(c) shows that in cases of downstream-going antidunes, $\bar{V} / A_{\mathrm{w}} \sqrt{g h}$ increases as $F$ increases; however, $A_{\mathrm{b}} / A_{\mathrm{w}}$ decreases as $F$ increases. The reason for this is that current not only pushes the antidune sand wave, but also flushes the bed form, and thus decreases its amplitude.

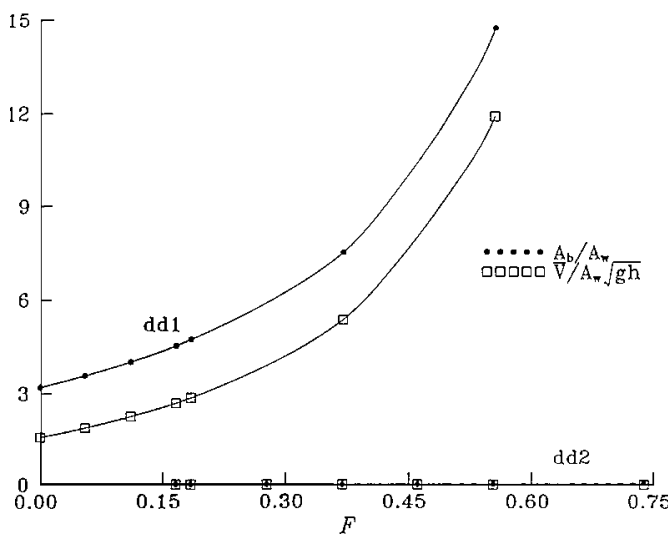

(a)

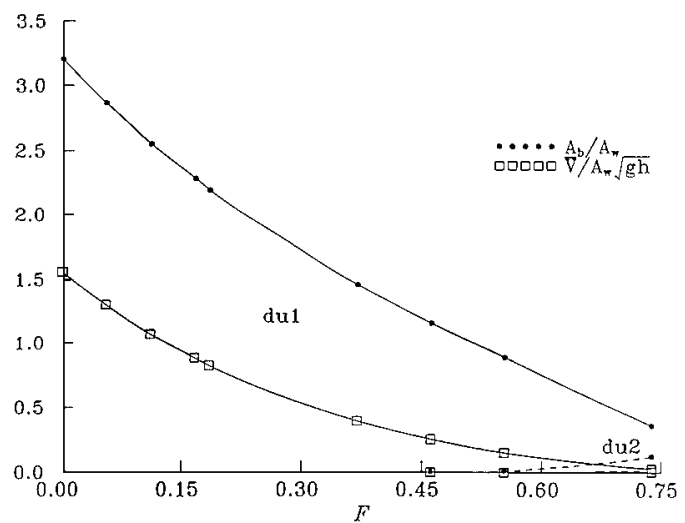

(b)

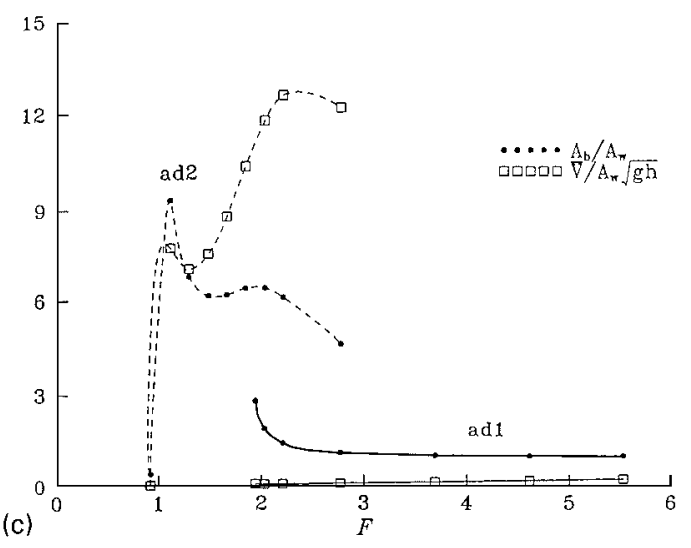

Figure 9. $A_{\mathrm{b}} / A_{\mathrm{w}}$ and $\bar{V} / A_{\mathrm{w}} \sqrt{g h}$ versus $F$ for very soft soil when $T=60 \mathrm{~s}$ and $h=3 \mathrm{~m}$; (a) downstreamgoing dune, (b) upstream-going dune, (c) downstream-going antidune. 


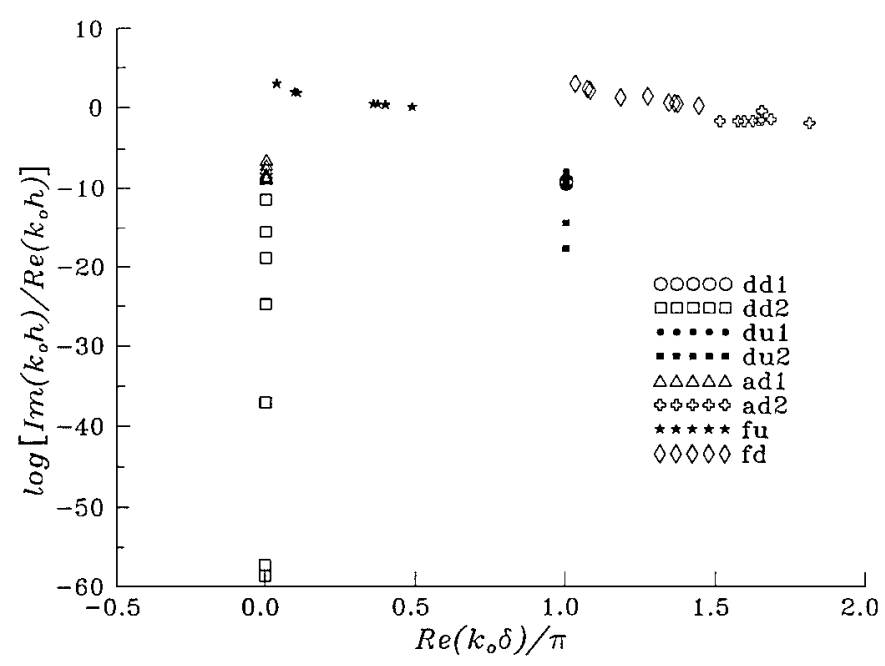

Figure 10. $\log \left[\operatorname{Im}\left(k_{0} h\right) / \operatorname{Re}\left(k_{0} h\right)\right]$ versus $\operatorname{Re}\left(k_{0} \delta\right) / \pi$ for very soft soil when $T=60 \mathrm{~s}$ and $h=3 \mathrm{~m}$.

Kennedy [9] suggested an unclear lagged distance $\delta$ of sediment discharge from flow velocity and which is exactly

$$
\delta=\theta^{\prime}-\theta^{\prime \prime}
$$

according to (76) and (69) of the present study. For the same examples as in Figures 7-9, we plot dissipation modulus, $\log \left[\operatorname{Im}\left(k_{0} h\right) / \operatorname{Re}\left(k_{0} h\right)\right]$, versus $\operatorname{Re}\left(k_{0} \delta\right) / \pi$ in Figure 10. The higher the value of the vertical axis of Figure 10, the higher the damping rate of the bed. We find from Figure 10 that flat bed fu, fd and a kind of large-amplitude antidune ad2 (see Figure 9) dissipate very quickly. We also find the remaining stable bed forms (no matter whether amplitude is large or small) either have $\operatorname{Re}\left(k_{0} \delta\right) / \pi=0(\operatorname{ad} 1, \mathrm{dd} 2)$ or have $\operatorname{Re}\left(k_{0} \delta\right) / \pi=1$ (dd1, du1, du2). Kenndy's [9] instability analysis found that only when $\operatorname{Re}\left(k_{0} \delta\right) / \pi$ equals 0 and 1 , there are stable bed forms; otherwise the bed forms are 'unstable'. Therefore we find from Figure 10 that the present solution not only gives exactly the same conclusion about $\delta$ for stable bed forms as in Kennedy [9], but also provides correct information on rapidly damping bed forms (instead of 'unstable' bed forms that grow to infinity given by Kennedy's [9] analysis) such as flat bed and some rapidly damping antidunes that Kennedy [9] did not have.

\section{CONCLUSIONS}

Instead of performing instability analysis and combining with an empirical sediment discharge formula as Kennedy [9] did, basing upon the observation and Kennedy's [9] success that the sandbed acts like a continuum for a long period of time, we solve a complete boundary-value problem of dune, antidune, and rapidly damping wave in the present work. In spite of employing different approaches, the present study confirms the stable dune and antidune of Kennedy [9], and also finds rapidly damping wave and the unclear lagged distance $\delta$ of sediment discharge from flow velocity that Kennedy [9] could not obtain. 
By applying the potential theory to the channel and adopting poroelasticity theory to the sandbed, the present study provides a new approach to solve the difficult erosion and deposition problem in river engineering. According to our analytical results, once the material properties of sandbed, water depth $h$, current speed $U$, water wave frequency $\omega$, water wave amplitude $A_{\mathrm{w}}$, and wave direction are known, the bed form is determined. However, due to large parameters such as $K, G, \lambda$, and small variables such as $\mathbf{d}, \mathbf{D}$, more practical numerical extensions of this work are expected to be very difficult. (The phenomena of a boundary layer near channel-water/sandbed interface and very small computing time steps will appear). Therefore, the result of the present work can also serve as a valuable and necessary verification for later complicated numerical studies.

\section{ACKNOWLEDGEMENTS}

The first writer, L. H. Huang, would like to dedicate this work to late Professor J. F. Kennedy, former director of the Iowa Institute of Hydraulic Research, the University of Iowa, for his outstanding pioneering contribution to the study of bed form deformation in alluvial channels. This study is supported by National Science Council of the Republic of China under grant NSC84-2211-E002-043.

\section{REFERENCES}

1. Darwin GH. On the formation of ripple-marks. Proceedings of the Royal Society of London, 1883-1884.

2. Sleath JFA. On rolling-grain ripples. Journal of Hydrological Research 1976; 14:69-81.

3. Blondeaux P. Sand ripples under sea waves. Part 1. Ripple formation. Journal of Fluid Mechanics 1990; 218:1-17.

4. Vittori G, Blondeaux P. Sand ripples under sea waves. Part 2. Finite-amplitude development. Journal of Fluid Mechanics 1990; 218:9-39.

5. Vittori G, Blondeaux P. Sand ripples under sea waves. Part 3. Brick-pattern ripple formation. Journal of Fluid Mechanics 1992; 239:23-45.

6. Exner FM. Über die Wechselwirkung zwischen Wasser und Geschiebe in Flussen. Sitzungsberichte der Akademie der Wissenschaften, Wein, Heft 3-4 (1925).

7. Liu HK. Mechanics of sediment-ripple formation. Journal of Hydrological Division, ASCE, 1957; 83:1-23.

8. Graf WH. Hydraulics of Sediment Transport. McGraw-Hill, New York. 1971.

9. Kennedy JF. The mechanics of dunes and antidunes in erodible-bed channels. Journal of Fluid Mechanics 1963; 16:521-544.

10. Huang LH, Song CH. Dynamic response of poroelastic bed to water waves. Journal of Engineering Mechanics, ASCE 1993; 119:1003-1020.

11. Huang LH, Chwang AT. Trapping and absorption of sound waves. II. A sphere covered with a porous layer. Wave Motion 1990; 12:401-414.

12. Biot MA. Mechanics of deformation and acoustic propagation in porous media. Journal of Applied Physics 1962; 33(4):1482-1498.

13. Morse PM, Feshbach H. Methods of Theoretical Physics. Vol II, 1978; McGraw-Hill. New York.

14. Chen TW, Huang LH, Song CH. Dynamic response of poroelastic bed to nonlinear water waves. Journal of Engineering Mechanics, ASCE 1997; 123:1041-1049. 